Background: Tofacitinib is an oral JAK inhibitor that is being investigated for JIA. Objectives: To assess tofacitinib efficacy and safety in JIA patients (pts).

Methods: This was a Phase 3, randomised, double-blind (DB), placebo (PBO)-controlled withdrawal study in pts aged $2-<18$ years with polyarticular course JIA (pcJIA), PsA or ERA (NCT02592434). In the 18-week open-label Part 1, pts received weight-based tofacitinib doses (5mg BID or lower). Pts with

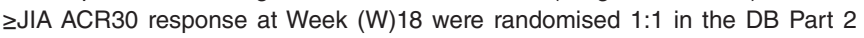
(W18-44) to continue tofacitinib or switch to PBO. Primary endpoint: disease flare rate by W44. Key secondary endpoints: JIA ACR50/30/70 response rates; change from Part 2 baseline $(\Delta)$ in CHAQ-DI at W44. Other efficacy endpoints: time to disease flare in Part 2; JADAS27-CRP in Parts 1 and 2. PsA/ERA pts were excluded from these efficacy analyses. Safety was evaluated in all pts up to W44. Results: 225 enrolled pts with pcJIA $(n=184)$, PsA $(n=20)$ or ERA $(n=21)$ received tofacitinib in Part 1. At W18, 173/225 (76.9\%) pts entered Part 2 (pcJlA n=142, PsA $n=15$, ERA $n=16$ ). In pcJIA pts, disease flare rate in Part 2 was significantly lower with tofacitinib vs PBO by W44 ( $p=0.0031$; Fig 1a). JIA ACR50/30/70 response rates (Fig 1b) and $\triangle \mathrm{CHAQ}-\mathrm{DI}$ (Fig 1c) at W44, and time to disease flare in Part 2 (Fig 2a), were improved with tofacitinib vs PBO. Tofacitinib reduced JADAS27-CRP in Part 1; this effect was sustained in Part 2 (Fig 2b). Overall, safety was similar with tofacitinib or PBO (Table): $77.3 \%$ and $74.1 \%$ had adverse events (AEs); $1.1 \%$ and $2.4 \%$ had serious AEs. In Part 1, 2 pts had herpes zoster (non-serious) and 3 pts had serious infections (SIs). In Part 2, Sls occurred in 1 tofacitinib pt and 1 PBO pt. No pts died.

Conclusion: In pcJIA pts, tofacitinib vs PBO resulted in significantly fewer disease flares, and improved time to flare, disease activity and physical functioning. Tofacitinib safety was consistent with that in RA pts.
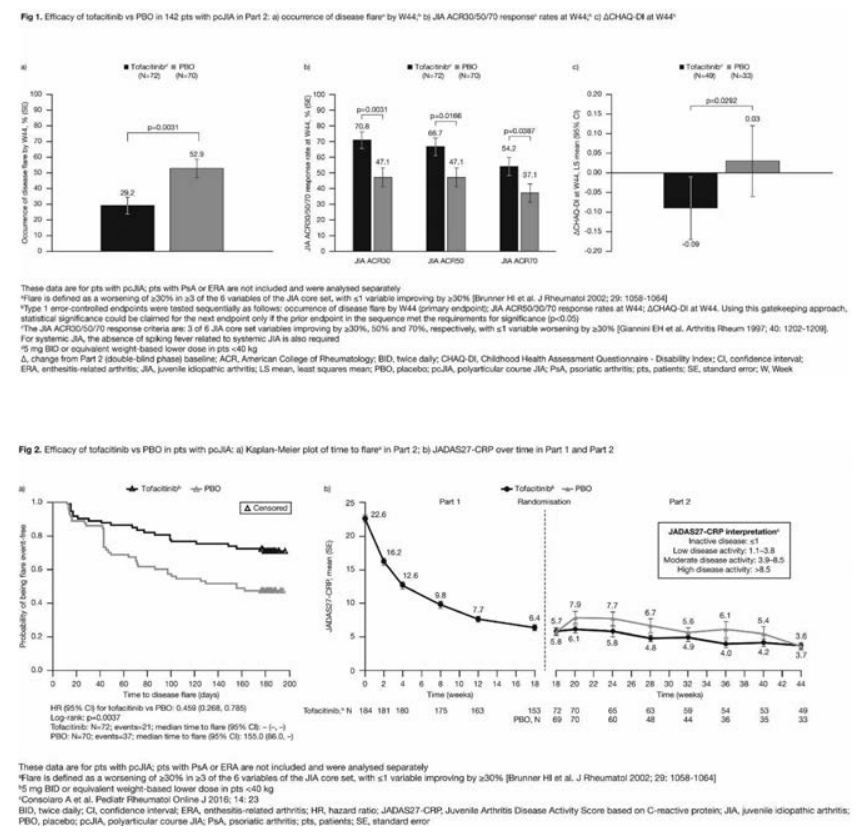

Acknowledgments: Study sponsored by Pfizer Inc. Medical writing support was provided by Sarah Piggott of CMC Connect and funded by Pfizer Inc.

Disclosure of Interests: Nicolino Ruperto Grant/research support from: Bristol-Myers Squibb, Eli Lily, F Hoffmann-La Roche, GlaxoSmithKline, Janssen, Novartis, Pfizer, Sobi (paid to institution), Consultant of: Ablynx, AbbVie, AstraZeneca-Medimmune, Biogen, Boehringer Ingelheim, Bristol-Myers Squibb, Eli Lily, EMD Serono, GlaxoSmithKline, Hoffmann-La Roche, Janssen, Merck, Novartis, Pfizer, R-Pharma, Sanofi, Servier, Sinergie, Sobi, Takeda, Speakers bureau: Ablynx, AbbVie, AstraZeneca-Medimmune, Biogen, Boehringer Ingelheim, Bristol-Myers Squibb, Eli Lily, EMD Serono, GlaxoSmithKline, Hoffmann-La Roche, Janssen, Merck, Novartis, Pfizer, R-Pharma, Sanofi, Servier, Sinergie, Sobi, Takeda, Olga Synoverska Speakers bureau: Sanofi, Tracy Ting: None declared, Carlos Abud-Mendoza Speakers bureau: Eli Lilly, Pfizer Inc, Alberto Spindler Speakers bureau: Eli Lilly, Yulia Vyzhga Grant/research support from: Pfizer Inc, Katherine Marzan Grant/research support from: Novartis, Vladimir Keltsev: None declared, Irit Tirosh: None declared, Lisa Imundo: None declared, Rita Jerath: None declared, Daniel Kingsbury: None declared, Betül Sözeri: None declared, Sheetal Vora: None declared, Sampath Prahalad Grant/ research support from: Novartis, Elena Zholobova Grant/research support from: Novartis and Pfizer Inc, Speakers bureau: AbbVie, Novartis, Pfizer Inc and Roche, Yonatan Butbul Aviel: None declared, Vyacheslav Chasnyk: None
Table. Safety in all pts

\begin{tabular}{|c|c|c|c|}
\hline & \multirow{2}{*}{ 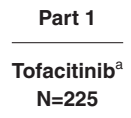 } & \multicolumn{2}{|c|}{ Part 2} \\
\hline & & $\begin{array}{l}\text { Tofacitinib }^{\mathrm{a}} \\
\mathrm{N}=88\end{array}$ & $\begin{array}{l}\text { PBO } \\
\mathrm{N}=85\end{array}$ \\
\hline \multicolumn{4}{|l|}{ Pts with events, $n(\%)$} \\
\hline AEs & $153(68.0)$ & $68(77.3)$ & $63(74.1)$ \\
\hline SAEs & $7(3.1)$ & $1(1.1)$ & $2(2.4)$ \\
\hline Permanent discontinuations due to AEs & $26(11.6)$ & $16(18.2)$ & $29(34.1)$ \\
\hline \multicolumn{4}{|l|}{ AEs of special interest } \\
\hline Death & 0 & 0 & 0 \\
\hline Gastrointestinal perforation ${ }^{b}$ & 0 & 0 & 0 \\
\hline Hepatic event ${ }^{\mathrm{b}}$ & $3(1.3)$ & 0 & 0 \\
\hline Herpes zoster (non-serious and serious) & $2(0.9)^{\mathrm{c}}$ & 0 & 0 \\
\hline Interstitial lung disease ${ }^{\mathrm{b}}$ & 0 & 0 & 0 \\
\hline Major adverse cardiovascular events ${ }^{b}$ & 0 & 0 & 0 \\
\hline $\begin{array}{l}\text { Malignancy (including non-melanoma skin } \\
\text { cancer) }^{\mathrm{b}}\end{array}$ & 0 & 0 & 0 \\
\hline Macrophage activation syndrome ${ }^{\mathrm{b}}$ & 0 & 0 & 0 \\
\hline Opportunistic infection $^{\mathrm{b}}$ & 0 & 0 & 0 \\
\hline SI & $3(1.3)$ & $1(1.1)^{d}$ & $1(1.2)$ \\
\hline $\begin{array}{l}\text { Thrombotic event (deep vein thrombo- } \\
\text { sis, pulmonary embolism }{ }^{\text {b }} \text { or arterial } \\
\text { thromboembolism) }\end{array}$ & 0 & 0 & 0 \\
\hline Tuberculosis ${ }^{\mathrm{b}}$ & 0 & 0 & 0 \\
\hline
\end{tabular}

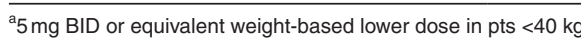

${ }^{\mathrm{b}}$ Adjudicated events

${ }^{\mathrm{c}}$ Both non-serious

${ }^{d}$ One SAE of pilonidal cyst repair was coded to surgical procedures instead of infections, and was inadvertently not identified as an SI. Following adjudication, the SAE did not meet opportunistic infection criteria; it is also included in the table as an $\mathrm{SI}$

$A E$, adverse event; $B I D$, twice daily; $P B O$, placebo; pts, patients; $S A E$, serious $A E ; S I$, serious infection

declared, Melissa Lerman Grant/research support from: Amgen, Kabita Nanda Grant/research support from: Abbott, AbbVie, Amgen and Roche, Heinrike Schmeling Grant/research support from: Janssen, Pfizer Inc, Roche and USB Bioscience, Heather Tory: None declared, Yosef Uziel Speakers bureau: Pfizer Inc, Diego O Viola Grant/research support from: Bristol-Myers Squibb, GSK, Janssen and Pfizer Inc, Speakers bureau: AbbVie and Bristol-Myers Squibb, Holly Posner Shareholder of: Pfizer Inc, Employee of: Pfizer Inc, Keith Kanik Shareholder of: Pfizer Inc, Employee of: Pfizer Inc, Ann Wouters Shareholder of: Pfizer Inc, Employee of: Pfizer Inc, Cheng Chang Shareholder of: Pfizer Inc, Employee of: Pfizer Inc, Richard Zhang Shareholder of: Pfizer Inc, Employee of: Pfizer Inc, Irina Lazariciu Consultant of: Pfizer Inc, Employee of: IQVIA, MingAnn Hsu Shareholder of: Pfizer Inc, Employee of: Pfizer Inc, Ricardo Suehiro Shareholder of: Pfizer Inc, Employee of: Pfizer Inc, Alberto Martini Consultant of: AbbVie, Eli Lily, EMD Serono, Janssen, Novartis, Pfizer, UCB, Daniel J Lovell Consultant of: Abbott (consulting and PI), AbbVie (PI), Amgen (consultant and DSMC Chairperson), AstraZeneca, Boehringer Ingelheim, Bristol-Myers Squibb (PI), Celgene, Forest Research (DSMB Chairman), GlaxoSmithKline, Hoffman-La Roche, Janssen (co-PI), Novartis (consultant and PI), Pfizer (consultant and PI), Roche (PI), Takeda, UBC (consultant and PI), Wyeth, Employee of: Cincinnati Children's Hospital Medical Center, Speakers bureau: Wyeth, Hermine Brunner Consultant of: Hoffman-La Roche, Novartis, Pfizer, Sanofi Aventis, Merck Serono, AbbVie, Amgen, Alter, AstraZeneca, Baxalta Biosimilars, Biogen Idec, Boehringer, Bristol-Myers Squibb, Celgene, EMD Serono, Janssen, Medlmmune, Novartis, Pfizer, and UCB Biosciences, Speakers bureau: GSK, Roche, and Novartis

DOI: 10.1136/annrheumdis-2020-eular.396

\section{OP0292 HIGH EFFICACY OF CANAKINUMAB IN SYSTEMIC JUVENILE IDIOPATHIC ARTHRITIS (SJIA) ACROSS AGE GROUPS: COMPARISON OF CHILDREN, ADOLESCENTS AND YOUNG ADULTS BASED ON POOLED CLINICAL TRIAL RESULTS}

$\underline{\text { P. Quartier }}^{1}$, E. Feist ${ }^{2}$, D. J. Lovell ${ }^{3}$, H. Umebayashi ${ }^{4}$, N. Ruperto ${ }^{5}$, H. Brunner ${ }^{3}$, C. Dunger-Baldauf ${ }^{6}$, S. Noviello ${ }^{7}$, S. Whelan ${ }^{8} .{ }^{1}$ Necker Hospital, Université de Paris, Paris, France; ${ }^{2}$ Helios Department of Rheumatology, VogelsangGommern, Germany; ${ }^{3}$ Cincinnati Children's Hospital Medical Center, Cincinnati, United States of America; ${ }^{4}$ Miyagi Children's Hospital, Miyagi, Japan; ${ }^{5}$ Clinica Pediatrica e Reumatologia, IRCCS Istituto Giannina Gaslini, Genoa, Italy; ${ }^{6}$ Novartis Pharma AG, Basel, Switzerland; ${ }^{7}$ Novartis Pharmaceuticals Corporation, East Hanover, United States of America; ${ }^{8}$ Novartis Ireland Limited, Dublin, Ireland 
Background: Still's disease is a systemic auto-inflammatory disease with a pediatric form, SJIA, and an analogous condition in adults, adult-onset Still's disease (AOSD). The role of interleukin-1 (IL-1) in the pathophysiology of Still's disease is well established. Canakinumab, a monoclonal antibody against IL-1B, is approved to treat patients with Still's disease in Europe (SJIA and AOSD) and the United States (SJIA).

Objectives: To study the efficacy of canakinumab in SJIA patients categorized by age, we performed an intention-to-treat analysis of pooled data from 5 clinical trials, as an addition to a previously communicated analysis including 3 of the studies ${ }^{1}$ Methods: The age categories were children ( $2-<12$ years), young adolescents $(12-<16$ years) and older adolescents and young adults $(16-<20$ years). We pooled efficacy results from patients with active disease at baseline treated during a 12-week period with canakinumab ( $4 \mathrm{mg} / \mathrm{kg}$ every 4 weeks), including the presence of intermittent fever, serum concentrations of $C$ reactive protein (CRP), improvement of SJIA (adapted pediatric ACR 30, 70 and 100 responses) and JIA ACR inactive disease status. Safety was assessed by analysis of reported adverse events (AEs).

Results: 302 children, 82 young adolescents and 34 older adolescents and young adults were included in the analysis, with a mean disease duration of 922 , 1708 and 2615 days, respectively. Prior therapy with other biologics was common, with anakinra used in $33 \%, 35 \%$ and $47 \%$ of patients in each group. Disease severity was comparable among groups, with the mean number of active joints ranging from 11.8 to 13.7. Adapted pediatric ACR responses revealed a rapid response to canakinumab, with all groups showing similar rates of responders at most time points (Table 1). In each age group, the proportion of patients with inactive disease progressively increased to Day 57. At all time points after Day 15 , the $16-<20$ years group presented the highest proportion of patients with inactive disease. Median CRP levels decreased from baseline to reach values in the normal range $(<10 \mathrm{mg} / \mathrm{L})$ from Day 29 onwards in the three groups, with improvements more marked in the $16-<20$ years group. The safety profile was similar in the three age groups analyzed, with a lower proportion of $16-<20$ years old patients experiencing serious AEs (28\%) as compared to children (35\%) and young adolescents (42\%).

Table 1. Percentages of patients with Adapted pediatric ACR responses and inactive disease status over time*

\begin{tabular}{ccccc}
\hline & $\begin{array}{c}\text { Time of treatment } \\
\text { (Days) }\end{array}$ & $2-<12$ years $^{\mathrm{a}}$ & $12-<16$ years $^{\mathrm{b}}$ & $16-<20$ years $^{\mathrm{c}}$ \\
\hline ACR30 & 15 & 72.7 & 81.7 & 83.9 \\
$(\%)$ & 29 & 77.5 & 84.1 & 82.4 \\
& 57 & 76.2 & 82.9 & 88.2 \\
ACR70 & 85 & 65.5 & 74.5 & 83.3 \\
$(\%)$ & 15 & 51.5 & 58.3 & 64.5 \\
& 29 & 61.9 & 62.2 & 70.6 \\
ACR100 & 57 & 65.2 & 58.5 & 79.4 \\
$(\%)$ & 85 & 58.6 & 61.8 & 75.0 \\
& 15 & 21.6 & 25.0 & 12.9 \\
Inactive disease & 29 & 29.5 & 30.5 & 35.3 \\
$(\%)$ & 57 & 36.1 & 34.1 & 38.2 \\
& 85 & 34.1 & 30.9 & 33.3 \\
& 15 & 19.0 & 30.0 & 19.4 \\
& 29 & 34.1 & 34.1 & 47.1 \\
& 57 & 39.4 & 36.6 & 55.9 \\
& 85 & 36.7 & 43.4 & 52.2 \\
\hline
\end{tabular}

*Some studies did not include visits at Day 15 and/or 85. For Day 15, 29, 57 and 85 the respective denominators for each age group were: ${ }^{\mathrm{a}} \mathrm{N}=231,302,302,232 ;{ }^{\mathrm{b}} \mathrm{N}=60,82,82$, $55 ;{ }^{\mathrm{c}} \mathrm{N}=31,34,34,24$.

Conclusion: The efficacy and safety profile of canakinumab was consistent in children, adolescents and young adults with SJIA. Since SJIA and AOSD represent pediatric- and adult- onset variants of the Still's disease continuum, these results further support the therapeutic effect of canakinumab $4 \mathrm{mg} / \mathrm{kg}$ every 4 weeks in both children and adults with Still's disease.

References:

[1] Feist et al. Clin Exp Rheumatol. 2018;36(4):668-75

Disclosure of Interests: Pierre Quartier Consultant of: AbbVie, Chugai-Roche, Lilly, Novartis, Sanofi, Sobi, Speakers bureau: AbbVie, BMS, Chugai-Roche, Novartis, Pfizer, Sobi, Eugen Feist Consultant of: Novartis, Roche, Sobi, Lilly, Pfizer, Abbvie, BMS, MSD, Sanofi, Speakers bureau: Novartis, Roche, Sobi, Lilly, Pfizer, Abbvie, BMS, MSD, Sanofi, Daniel J Lovell Consultant of: Abbott (consulting and PI), AbbVie (PI), Amgen (consultant and DSMC Chairperson), AstraZeneca, Boehringer Ingelheim, Bristol-Myers Squibb (PI), Celgene, Forest Research (DSMB Chairman), GlaxoSmithKline, Hoffman-La Roche, Janssen (co-PI), Novartis (consultant and PI), Pfizer (consultant and $\mathrm{PI})$, Roche (PI), Takeda, UBC (consultant and PI), Wyeth, Employee of: Cincinnati Children's Hospital Medical Center, Speakers bureau: Wyeth, Hiroaki Umebayashi: None declared, Nicolino Ruperto Grant/research support from: Bristol-Myers Squibb, Eli Lily, F Hoffmann-La Roche, GlaxoSmithKline, Janssen, Novartis, Pfizer,
Sobi (paid to institution), Consultant of: Ablynx, AbbVie, AstraZeneca-Medimmune, Biogen, Boehringer Ingelheim, Bristol-Myers Squibb, Eli Lily, EMD Serono, GlaxoSmithKline, Hoffmann-La Roche, Janssen, Merck, Novartis, Pfizer R-Pharma, Sanofi, Servier, Sinergie, Sobi, Takeda, Speakers bureau: Ablynx, AbbVie, AstraZeneca-Medimmune, Biogen, Boehringer Ingelheim, Bristol-Myers Squibb, Eli Lily, EMD Serono, GlaxoSmithKline, Hoffmann-La Roche, Janssen, Merck, Novartis, Pfizer, R-Pharma, Sanofi, Servier, Sinergie, Sobi, Takeda, Hermine Brunner Consultant of: Hoffman-La Roche, Novartis, Pfizer, Sanofi Aventis, Merck Serono, AbbVie, Amgen, Alter, AstraZeneca, Baxalta Biosimilars, Biogen Idec, Boehringer, Bristol-Myers Squibb, Celgene, EMD Serono, Janssen, Medlmmune, Novartis, Pfizer, and UCB Biosciences, Speakers bureau: GSK, Roche, and Novartis, Cornelia Dunger-Baldauf Employee of: Novartis, Stephanie Noviello Employee of: Novartis, sarah whelan Employee of: Novartis DOI: 10.1136/annrheumdis-2020-eular.3759

\section{OP0293 USE OF WHOLE-BODY MAGNETIC RESONANCE TO IDENTIFY POTENTIAL DIAGNOSTIC CLUES IN CHILDREN WITH FEVER OF UNKNOWN ORIGIN (FUO)}

S. Signa ${ }^{1,2}$, R. Caorsi ${ }^{1}$, G. Stagnaro ${ }^{3}$, F. Minoia $^{4}$, P. Picco ${ }^{4}$, A. Ravelli ${ }^{2,4}$, M. B. Damasio ${ }^{3}$, M. Gattorno ${ }^{1} .{ }^{1}$ IRCCS Istituto Giannina Gaslini, UOSD Centro Malattie Autoinfiammatorie ed Immunodeficienze, Genoa, Italy; ${ }^{2}$ University of Genoa, DINOGMI, Genoa, Italy; ${ }^{3}$ IRCCS Istituto Giannina Gaslini, UOC Radiologia, Genoa, Italy; ${ }^{4}$ IRCCS Istituto Giannina Gaslini, UOC Clinica Pediatrica e Reumatologia, Genoa, Italy

Background: Whole-body magnetic resonance imaging (WBMRI) is a fast and accurate method to detect diseases throughout the entire body without exposure to ionizing radiation. Possible emerging applications for this technique include rheumatologic field and evaluation of fever of unknown origin (FUO).

Objectives: To evaluate the ability of WBMRI to identify significant potential diagnostic clue (PDC) in patients presenting a non specific inflammatory clinical picture.

Methods: We retrospectively collected cases of pediatric patients followed in a single pediatric rheumatology center who underwent WBMRI between January 2010 and December 2015 for the following indications: i) FUO (temperature greater than $38.3^{\circ} \mathrm{C}$ for more than three weeks or failure to reach diagnosis after one week of investigations), iii) recurrent fever (febrile episodes separated by periods of normal temperature), iii) Inflammation of unknown origin, IUO (an illness of at least 3 weeks' duration, with raised inflammatory markers and fever below $38.3^{\circ} \mathrm{C}$ ).WBMRI studies were acquired with coronal and sagittal planes (slice thickness $5 \mathrm{~mm}$ ) with acquisition of several image sets with automatic direct image realignment after acquisition creating a whole-body scan.Sequences include short $\mathrm{\tau}$ inversion recovery (STIR) and T1-weighted. All studies have been evaluated twice, the second time according to a predefined checklist, defined by an experienced radiologist, considering systematically single /multifocal bone lesion, bone marrow, joint effusion, soft tissues, adenopathies, parenchymal and vessels looking for PDC. We considered as a Potential Diagnostic Clue each alteration of the examined district that can potentially guide the diagnosis. Each alteration found is a PDC. We retrospectively evaluated patients' clinical history and final diagnosis and we classified the PDCs identified during both first evaluation and re-evaluation as: Not useful (the identified PDC did not guide the diagnosis and is not coherent with the final diagnosis), consistent (the identified PDC is congruent with the patient's final diagnosis) or diagnostic (the identification of the considered PDC strongly orient the final diagnosis).

Results: We collected 104 patients who underwent WBMRI; 24 (23\%) of them presenting FUO, 28 (27\%) presenting recurrent fever and $52(50 \%)$ presenting IUO. The mean age of onset symptoms was 6 years and nine months (range: 2 weeks old- 17 years and 6 months). The mean age of execution of WBMRI was 9 years (range: 5 months old- 19 years). After the whole diagnostic work-out a final diagnosis was achieved in 44 patients (42\%).PDCs were identified at the first evaluation in $78 / 104$ cases $(75 \%)$. In 22 cases $(21 \%)$ the identified PDCs were consistent with the diagnosis, whereas in 9 cases $(8.5 \%)$ the identified PDCs were considered diagnostic. Globally we can consider that at first evaluation PDCs were somehow contributory to the diagnosis in 31 cases $(30 \%$; 6 JIA, 7 systemic infections, 5 monogenic inflammatory diseases, 4 ALPS, 2 Goldbloom's Syndrome,2 Vasculitis, 1 eosinophilic fasciitis, 1 hystiocytosis, 3 oncologic diagnosis).Blind re-evaluation of WBMRI allowed the identification of additional PDCs in 52 patients (12 of them previously negative). In 10 cases the PDC found after re- evaluation were consistent with the final diagnosis (2 JIA one infectious disease, one neuroblastoma, 3 ALPS, 1 monogenic inflammatory disease, 1Takayasu arteritis, 1 Goldbloom's syndrome).

Conclusion: WBMRI can be a powerful diagnostic tool in patients with FUO. A predefined checklist increases sensitivity of WBMRI in the identification of PDC. Disclosure of Interests: Sara Signa: None declared, Roberta Caorsi: None declared, Giorgio Stagnaro: None declared, Francesca Minoia: None declared, Paolo Picco: None declared, Angelo Ravelli: None declared, Maria Beatrice 